\title{
EU Developments of the ITER ECRH System
}

\section{M.A Henderson}

and Ansaldo, CEA, CRPP-EFPL, EFDA, ENEA-CNR, FOM, FZK, IPF, IPP, OCEM, THALES, TEKES (complete author list in conference proceedings)

\section{CRPP - EPFL, Lausanne, Switzerland}

The electron cyclotron (EC) heating and current drive (H\&CD) system of ITER will deliver $20 \mathrm{MW} / \mathrm{CW}$ in the plasma at $170 \mathrm{GHz}$ for $\mathrm{H} \& \mathrm{CD}$ in addition to $2.5 \mathrm{MW} / 3 \mathrm{~s}$ at $120 \mathrm{GHz}$ for plasma start-up. The EC system is composed of power supplies (PS), up to $24 \mathrm{H} \& \mathrm{CD}$ gyrotrons (1 to $2 \mathrm{MW}$ tubes), 3 start-up gyrotrons (1MW tubes), 24 transmission lines and two sets of launching antennas: equatorial (EL) and upper (UL) launchers. Under the present ITER procurement package the EU is responsible for one third of the H\&CD $170 \mathrm{GHz}$ gyrotrons, all PSs associated with the H\&CD system, and the whole set (4) of upper launchers.

In all areas of participation, the EU EC partnership (coordinated by the European Fusion Development Association - EFDA) aims toward advancing the technology of each of these subsystems. For example, procurement of Pulse Step Modulator (PSM) HVPS is under consideration, which might have equivalent costs to the present ITER design (thyristor HVPS and HV series switch), but with an increased flexibility in operation and variation in the EC power waveform. The EU is at the forefront in gyrotron research and is developing a $2 \mathrm{MW} \mathrm{CW} 170 \mathrm{GHz}$ coaxial cavity gyrotron offering an increase in output power while maintaining moderate power densities in the gyrotron cavity and collector. THALES ${ }^{\circledR}$ in collaboration with its EFDA partners (FZK, CRPP, TEKES) is manufacturing a series of prototype tubes in three phases of typically $1 \mathrm{~s}, 100 \mathrm{~s}$ and then $\mathrm{CW}$ pulse capacity $(\sim 2010)$. A $2 \mathrm{MW}, \mathrm{CW}$ gyrotron test facility is being built at CRPP that will be used to develop the 2MW coaxial tube, in addition to testing various components required by the EC system.

EFDA has undertaken a parallel development of two launcher options: front (FS) and remote (RS) steering, with the aim of providing an optimum launcher for ITER weighing EC physics aspects and operation reliability. The FS launcher (ITER reference design) offers a significant enhancement in physics performance, while the RS (backup solution) offers a remote steering mirror far from the plasma for simplified ex-vessel maintenance access. The principle role of the UL is to stabilise neoclassical tearing modes. However, an enhanced performance UL launcher is under investigation by EFDA, seeking synergy between the EL and UL that would extend the physics potential of both launchers for an enhanced ITER EC physics performance, while at the same time relax some of the engineering requirements. 